\title{
Identifying Vegetation Dynamics and Sensitivities in Response to Water Resources Management in the Heihe River Basin in China
}

\author{
Dongqin Yin, ${ }^{1}$ Xiang Li, ${ }^{2}$ Yuefei Huang, ${ }^{1}$ Yuan Si, ${ }^{1}$ and Rui Bai ${ }^{1}$ \\ ${ }^{1}$ State Key Laboratory of Hydro-Science \& Engineering, Tsinghua University, Beijing 100084, China \\ ${ }^{2}$ State Key Laboratory of Simulation and Regulation of Water Cycle in River Basin, China Institute of Water Resources and \\ Hydropower Research, Beijing 100038, China
}

Correspondence should be addressed to Yuefei Huang; yuefeihuang@tsinghua.edu.cn

Received 27 November 2014; Revised 18 January 2015; Accepted 20 January 2015

Academic Editor: Yongqiang Zhang

Copyright ( 2015 Dongqin Yin et al. This is an open access article distributed under the Creative Commons Attribution License, which permits unrestricted use, distribution, and reproduction in any medium, provided the original work is properly cited.

The Heihe River Basin, the second largest inland river basin in China, plays a vital role in the ecological sustainability of the Hexi Corridor. However, the requirements for regional economic development and ecological balance cannot be fully met due to water resource shortage and overexploitation induced by an extremely dry climate and population growth, especially in the middle and lower basins. Thus, environmental conservation projects that reallocate water resources have been planned and implemented step by step since 2001. The aim of this study is to evaluate ecosystem restoration benefits by identifying vegetation dynamics and sensitivities. The MODIS Normalized Difference Vegetation Index (NDVI) and its derivative indices, coupled with Geographic Information System (GIS), are introduced to explore ecosystem evolution at the pixel level, based on the hydrological and meteorological data in the whole region at varying temporal and spatial scales. Results indicate there are slight vegetation restoration trends in the upper, middle, and lower basin; the results of correlation analyses between vegetation and runoff into the lower basin suggest that the impact of a water supplement lasts at most three years, and engineering or nonengineering measures should be maintained for permanent ecosystem recovery.

\section{Introduction}

The Heihe River Basin (HRB, see Figure 1), the second largest inland river basin in China, plays a vital role in sustaining ecological balance in the Hexi Corridor. However, in recent decades, the HRB has suffered serious ecosystem degradation and desertification due to its extreme dry climate and population growth, particularly in the middle and lower basins [1-3]. The water resource situation of the HRB can be summarized in two major points. (1) Water resource shortage: the continental climate of the whole basin affects the water resource availability. The mean annual precipitation drops from $140 \mathrm{~mm}$ in the southwest to $47 \mathrm{~mm}$ in the northeast, whereas the mean annual evaporation increases from $1410 \mathrm{~mm}$ to $2250 \mathrm{~mm}$. Most areas in the HRB, approximately
93\% of the total basin, hardly yield runoff in the middle and lower basins. (2) Water resource overexploitation: with the rapid social and economic development, the sharp increase in water consumption in the middle basin for living and production uses (from 1.5 billion $\mathrm{m}^{3}$ in the early 1950s to 2.45 billion $\mathrm{m}^{3}$ in the late 1990s) has resulted in a continuous decrease in runoff into the lower basin (from 1.16 billion $\mathrm{m}^{3}$ to 0.77 billion $\mathrm{m}^{3}$ ). Water usage waste and inefficiency are rather serious, resulting from unmanaged and unsupervised water resources in the whole basin. Thus, ecological problems of varying extents appear; specifically, natural forest and grassland degradation and biodiversity loss occur in the upper basin; soil salinization and desertification occur in the middle basin; and a series of prominent problems such as zero-flow rivers, dried-up lakes (the East and West Juyan 


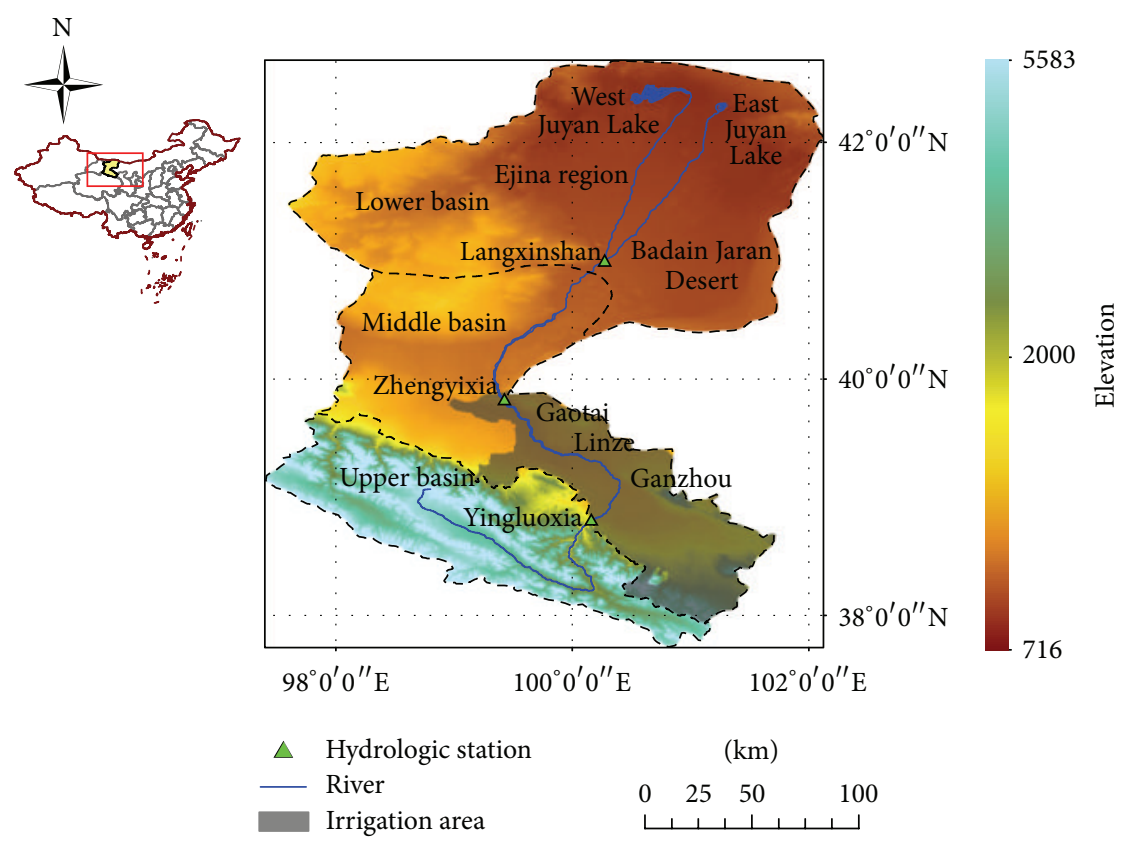

Figure 1: Map of study area.

Lakes), declining water tables, and a sharp reduction in natural forest and grassland areas occur in the lower basin, aggravating desertification and sandstorms.

Because of ecological problems resulting from water resource shortage and overexploitation, the near-term environmental conservation program (NTECP) has been planned and implemented for the HRB since 2001 by the Ministry of Water Resources (MWR) in China [4]. The objective of the NTECP is to reallocate water resources between ecological system maintenance and social-economic development. Moreover, the allowable water resource amounts have also been reallocated among upper, middle, and downstream river basin. In the upper basin, ecological restoration projects were implemented including forest and grassland conservation and artificial afforestation. Water-saving projects, especially for the irrigation regions, were undertaken in the middle river basin to ensure enough water releasing into the lower basin. The projects, such as water diversion canal construction, river regulation, irrigation system improvement, and grazing control, have been implemented in the lower basin for ensuring sufficient water reaching the most downstream region, where ecological system is significantly vulnerable.

Vegetation has a significant impact on interactions between terrestrial ecosystems and atmospheric processes $[5,6]$. Identifying the response mechanisms of vegetation dynamics and sensitivities to water resource availability at varying temporal and spatial scales makes it possible to evaluate the ecosystem restoration benefits. For a long time, the response of vegetation variability to air, water, and soil has been an active study subject because of various natural and cultural statuses in the context of changing climate and frequent human activities [7-9]. Water resource availability dominates the temporal-spatial distributions and dynamics of vegetation, which maintains a regional ecosystem $[10,11]$.
Past studies indicate that climate change affects water resource availability in the long term, and human activities have recently become more dominant in the short term, particularly in arid and semiarid regions with high population density but limited water resources $[12,13]$. In general, rainfall and runoff are the two major direct water sources for nourishing regional vegetation. However, in an arid/semiarid region, the rainfall is so scarce that it plays little role in supplying water, making runoff the major water source $[14,15]$. It is necessary to study the underlying correlations between vegetation and hydrometeorological impact factors to better manage limited water resources for ecosystem conservation or restoration in arid and semiarid regions.

Because there is little field survey data, remote sensingbased vegetation indices have been widely used to study land uses and cover changes, including the Normalized Difference Vegetation Index (NDVI) [16], the perpendicular vegetation index (PVI) [17], soil-adjusted vegetation index (SAVI) [18], and green index (GI) [19]. The NDVI is the normalized difference between the near-infrared reflectance and visible red waveband $[16,20]$. It reflects the vigor and greenness of the vegetation canopy by measuring the chlorophyll content changes using visible red radiation absorption and by measuring spongy mesophyll changes using near-infrared radiation reflection [21]. The NDVI and its derivative indices such as coefficient of variation (CV) [22] and vegetation condition index (VCI) [23] have been proved effective for vegetation dynamics identification $[24,25]$. The NDVI has also been successfully applied in many other fields, including land cover classification [26], plant phenology [27], drought assessment [28], and evapotranspiration estimation [29].

In this paper, ecosystem restoration benefits are evaluated by identifying vegetation dynamics and sensitivities since the environmental conservation projects in the HRB were 


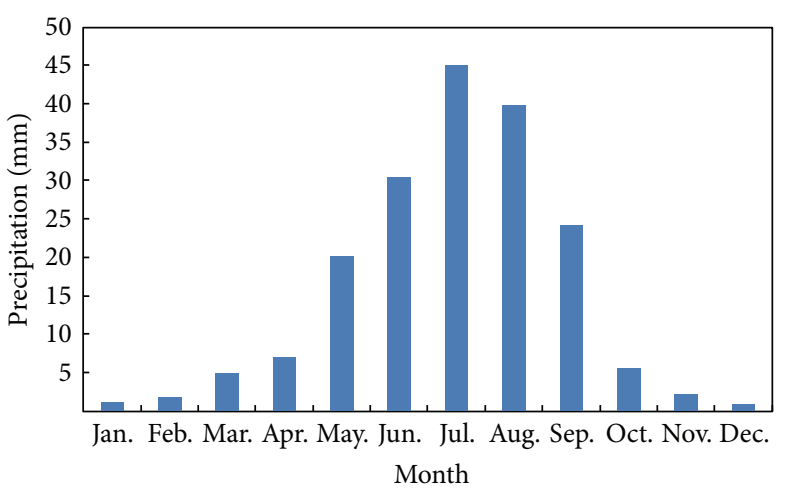

(a) Monthly mean precipitation

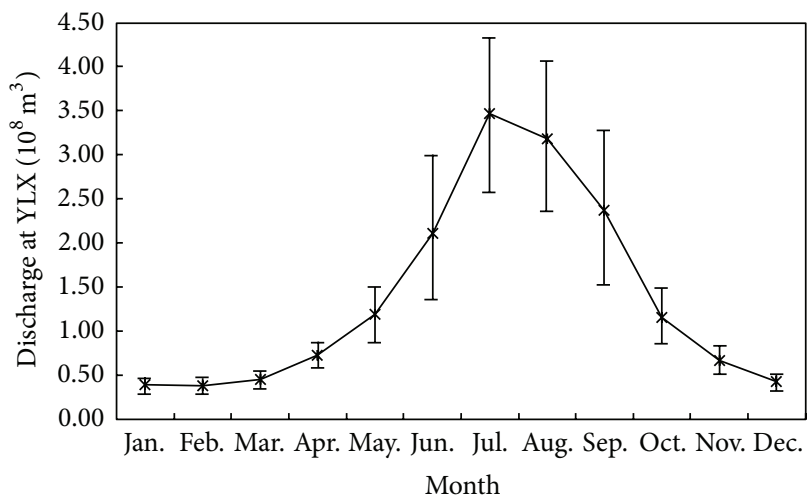

(c) Monthly mean runoff at the Yingluoxia station

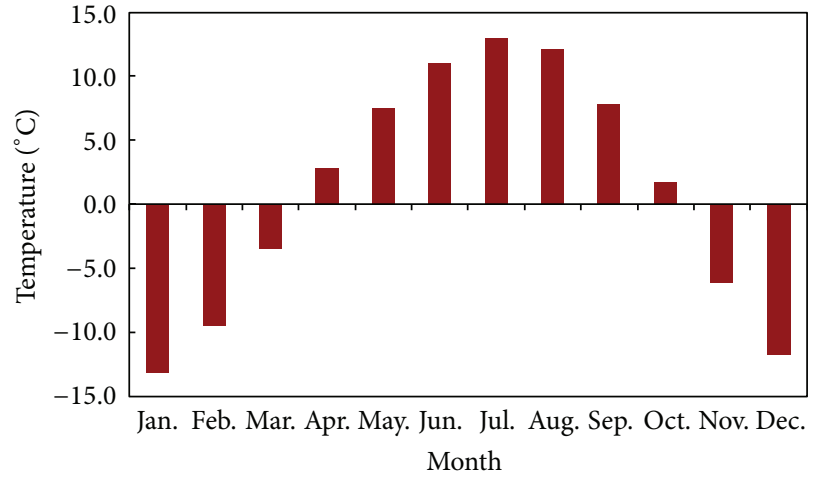

(b) Monthly mean temperature

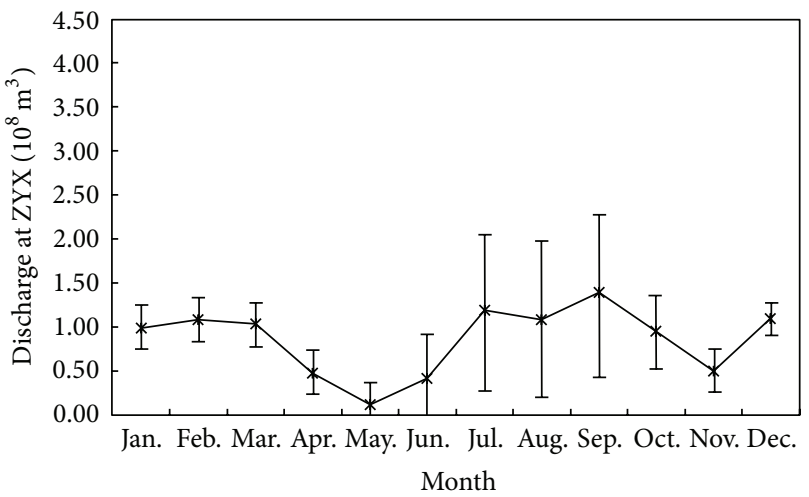

(d) Monthly mean runoff at the Zhengyixia station

Figure 2: Meteorological and hydrological conditions in the Heihe River Basin (1957-2010). * Bars indicate standard deviation of monthly runoff during 1957-2010.

planned and implemented in 2001. This paper differs from previous efforts $[2,30-32]$ through investigating vegetation dynamics in the upper, middle, and lower HRB after implementation of the NTECP. Additionally, vegetation sensitivities and the corresponding time lags of vegetation change to water reallocation in the lower basin are quantitatively identified at the pixel level, rather than qualitatively at the regional scale. The paper is organized as follows: Section 2 describes the study area; Section 3 introduces the data acquisition and processing, along with the Normalized Difference Vegetation Index (NDVI), based on the MODIS images, along with its derivative indices, coupled with Geographic Information System (GIS); Section 4 explores the vegetation dynamics and sensitivities in response to the NTECP, using historical data from the entire region; and Section 5 presents conclusions and suggestions.

\section{Study Area}

The Heihe River Basin (HRB) is located in northwestern China, covering an area of approximately $14.29 \times 104 \mathrm{~km}^{2}$ (between $37^{\circ} 43^{\prime}-42^{\circ} 41^{\prime} \mathrm{N}$ and $97^{\circ} 23^{\prime}-102^{\circ} 72^{\prime} \mathrm{E}$ ), as shown in Figure 1. The Heihe River originates from the north of the Qilian Mountains in Qinghai Province, flows through the middle Hexi Corridor in Gansu Province, and reaches the Ejina basin in the Inner Mongolia Autonomous Region. The annual mean runoff generated from the Qilian Mountains (the Yingluoxia station) is approximately $16 \times 10^{8} \mathrm{~m}^{3}$ from both rainfall and melt water from glacier/snow in the mountain region. As shown in Figure 2(a), approximately $80 \%$ of precipitation occurs during the period of May to October. At this period the melt water from glacier/snow also significantly increases due to temperature rising (Figure 2(b)). Both of them result in runoff increase at the mountainous region (the Yingluoxia station, Figure 2(c)). However, irrigation in the middle Hexi Corridor consumes large amount of water, leading to little surface water recharge to the lower Ejina basin (the Zhengyixia station, Figure 2(d)). Therefore, the HRB can be characterized with its extreme dry climate with low precipitation, high potential evaporation, and low runoff.

The HRB is divided into the upper, middle, and lower reaches by the Yingluoxia (YLX) and Zhengyixia (ZYX) hydrologic stations, with lengths of $303 \mathrm{~km}, 185 \mathrm{~km}$, and $333 \mathrm{~km}$, respectively. The upper basin is characterized by a wet and cold climate and serves as the major runoff yield region, with annual precipitation of approximately $350 \mathrm{~mm} / \mathrm{yr}$. The elevation in this region is $2000-5000 \mathrm{~m}$, with steep topography, and the vegetation cover in the upper basin is diversified and complex. The mountainous zone in this region is covered with relatively dense vegetation (consisting of forest, shrub, and grassland), and the plain terrain contains oasis and gobi/desert. The middle basin is located in a dry 
environment with low annual precipitation $(60-160 \mathrm{~mm})$ and high annual potential evaporation (1000-2000 mm). The elevation in the middle basin is $1300-1700 \mathrm{~m}$, with relatively flat topography. Most of the areas in this region are artificial oases supported by highly developed irrigation systems with a history of more than 2000 years, with the fastest expansion of agricultural development occurring in the last 50 years. The lower basin is in an extremely arid environment with little annual precipitation (less than $100 \mathrm{~mm}$ ) and high annual potential evaporation (more than $3500 \mathrm{~mm}$ ). The elevation in the lower basin is $910-1450 \mathrm{~m}$, with very flat topography. The lower basin is covered mainly by Gobi and desert, except for regions close to the river. The Heihe River is separated into two branches at the Langxinshan station, that is, the East River and the West River, which end in the East and West Juyan Lake, respectively. Water usage in the middle and lower basins is primarily dependent on the runoff from the upper basin. The middle basin serves as the major water usage region for human beings (the population in the middle basin occupies approximately $94 \%$ of the whole river basin) and has an extensive irrigation system.

There are 10 cities/counties belonging to three provinces in the $\mathrm{HRB}$, and the total population is approximately 1.4 million, as of 2009. The upper HRB is dominated by shruband grassland-based animal husbandry, with a small amount of farming. Most areas in the middle HRB are covered by artificial oases $\left(3533 \mathrm{~km}^{2}\right)$ which consume large amounts of irrigation water. Part of the lower HRB, mainly the Ejina oasis, is composed of grassland-based animal husbandry. According to previous studies, the population in the HRB increased by more than 100,000 from 1999 to 2009, with the most dramatic increase occurring in the middle HRB (approximately $80 \%$ of the total increase). The irrigation area in the HRB increased by approximately $200 \mathrm{~km}^{2}$ from 1999 to 2009, with the most obvious increase also occurring in the middle HRB. Overall, the HRB can be summarized as a region with a shortage of water resources and a consistent increase in population and water consumption, which stress the water resources.

\section{Materials and Methods}

The geographic data, including the basin boundary, rivers and lakes, and the locations of hydrologic stations, were downloaded from the Cold and Arid Regions Science Data Center at Lanzhou (http://westdc.westgis.ac.cn/). The hydrological and meteorological data, including the historical runoff at hydrologic control stations (i.e., the Yingluoxia, the Zhengyixia, and the Langxinshan hydrologic stations) and precipitation, were collected from the Heihe River Bureau of the Yellow River Conservancy Commission and the CRU TS3.21 database [33], respectively.

The Normalized Difference Vegetation Index (NDVI) is acquired from the Terra-MODIS Vegetation Indices MOD13A1 products from the Earth Observing System of the National Aeronautics and Space Administration (NASA) [34]. These products provide the vegetation conditions with a 500-meter spatial resolution and a 16-day temporal resolution. For analysis, the time series of NDVI data from 2001 to 2010 are smoothed using the Savitzky-Golay filter to reduce noise [35], and only NDVI data for the vegetation growing season (from April to October) are selected to avoid distorted or low values [36,37]. Note that a higher NDVI value of a pixel represents more vegetation coverage, and a lower NDVI value represents less or no vegetation coverage.

To identify the vegetation dynamics at the pixel level, derivative indices based on NDVI data are introduced, including (1) annual mean of NDVI (referred to as the mean NDVI hereafter): this is the mean NDVI value from April to October of each year and represents the average overall state of vegetation coverage; (2) annual variation trend of NDVI: this depicts the linear regression of NDVI data through the year; the slope of the linear regression (referred to as the NDVI slope hereafter) can represent restoration when the value is positive and degradation otherwise and can therefore assist in qualitative and quantitative analyses of vegetation change direction and magnitude; (3) interannual coefficient of variation (CV) of NDVI: this is the dispersion of NDVI data over multiple years to its mean value; the value can indicate the variation amplitude at the pixel level, with a higher value representing a greater variation [22].

The impact of upstream runoff, that is, runoff at the Langxinshan (LXS) station, on vegetation in the Ejina region is expected to show a one-year lag due to agricultural activities and groundwater recharge [9]. To quantify the detailed distribution of time scales at the pixel level, we investigated the relation between anomalies of LXS runoff and NDVI at different time lags (0-4 years) by shifting runoff anomalies by one year at a time. In the correlation analyses, only the positive time lags are considered because the water supply generally leads the growth of vegetation. Additionally, the specific time lags between anomalies of NDVI and LXS runoff in these derived pixels are identified. The Pearson correlation analysis is used to analyze the relationship between runoff and vegetation to identify the vegetation sensitivities. Significant pixels are selected to produce a statistically valid value using the two-tailed $t$-test (where $P \leq 0.05$ means statistical significance).

\section{Results and Discussion}

4.1. Overall Vegetation Dynamics. The overall vegetation dynamics of the HRB are analyzed with the abovementioned indices. The mean NDVI, NDVI slope, and interannual CV from 2001 to 2010 are shown in Figures 3(a)-3(d). As shown in Figure 3(a), there is a high vegetation coverage in the upper basin but relatively low coverage in the middle basin (mostly distributed among the irrigation regions) and lower basin (mostly distributed among the riverside regions). Figures 3(b) and 3(c) show that the vegetation evolutions exhibit obvious distribution differences: vegetation restoration trends are distributed throughout most regions (depicted in green), but vegetation degradation trends still exist in a small portion of regions (depicted in red), mostly in the upper portion of the upper basin, the central irrigation region in the middle 


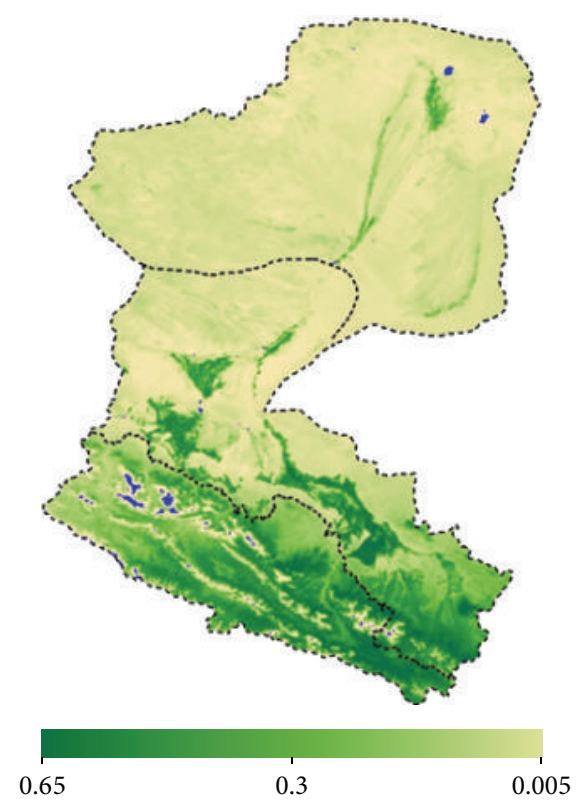

(a) Mean NDVI

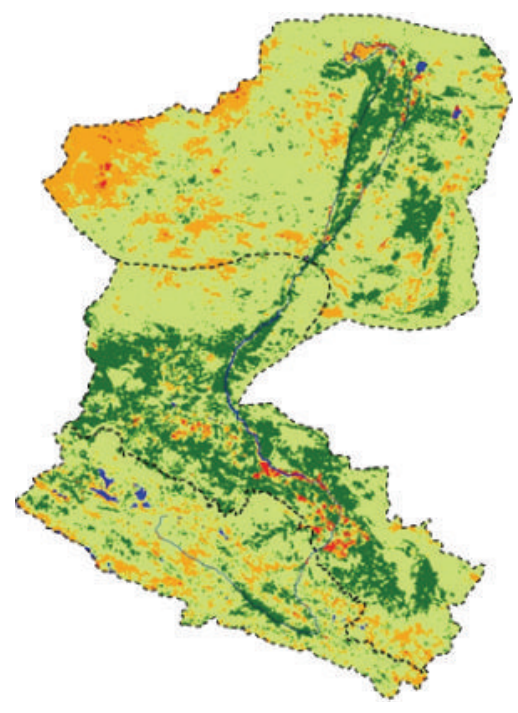

Significant increase

Nonsignificant increase

Significant decrease

Nonsignificant decrease

(c) Significance of NDVI slope

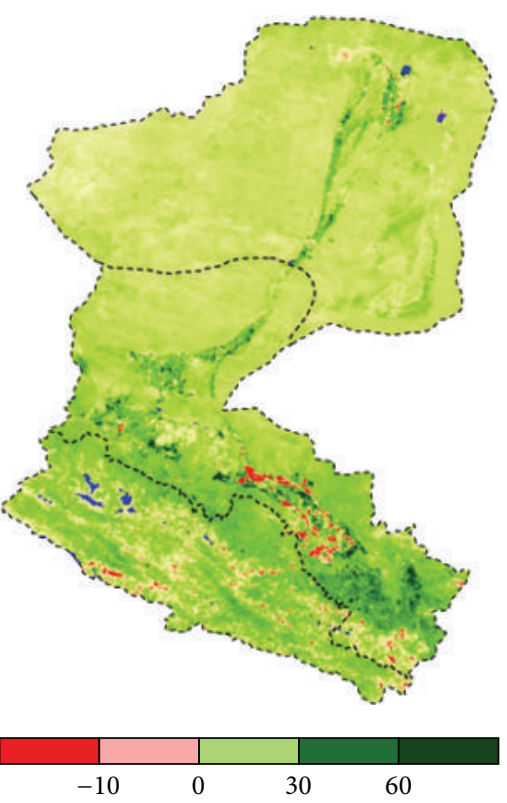

(b) NDVI slope

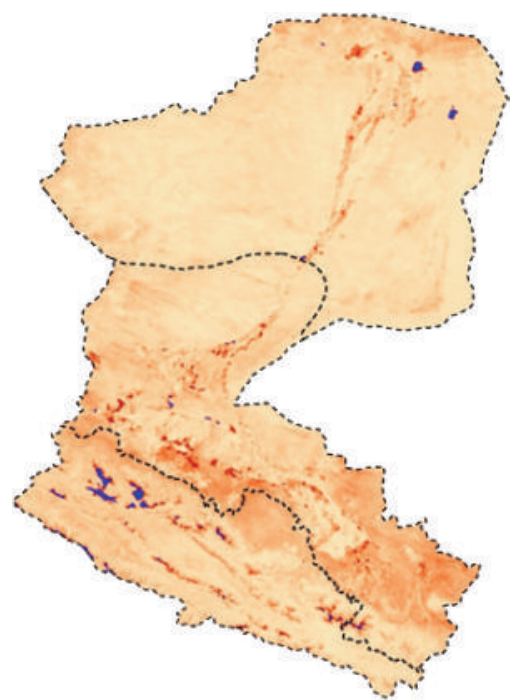

1.25
0.01

(d) Interannual CV

FIgURE 3: Vegetation dynamics in the Heihe River Basin.

basin, and the West Juyan Lake in the lower basin. As shown in Figure 3(c), the significant increase of vegetation mostly occurred in the middle and lower basins, rather than in the upper basin. Moreover, vegetation increase mostly occurred along the Heihe River in the upper and lower basins. In the middle basin, a large proportion of areas show significant improvement and a small region along the river in the Linze and Ganzhou County shows a significant decrease due to anthropogenic activities. The intensive restoration or degradation of vegetation in the irrigation region in the middle basin is probably due to the adjustment of irrigation areas since the implementation of environmental conservation projects in 2001. On average, vegetation has recovered at the whole basin scale since 2001; the overall vegetation restoration rates of the upper and middle basins are similar to each other and faster than in the lower basin, as the slopes of their linear regressions are similar to each other and larger than that of the lower basin (see Figure 4). 


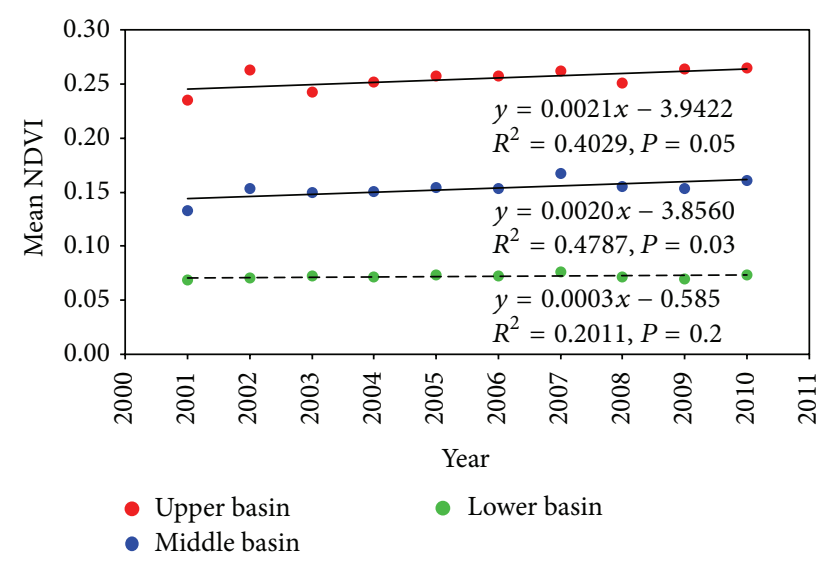

FIGURE 4: Vegetation evolutions of the upper, middle, and lower basins. ${ }^{*}$ Regression that is significant $(P \leq 0.05)$ or nonsignificant $(P>0.05)$ is presented with solid line or dashed line, respectively.

The vegetation variation is very small in the mean interannual $\mathrm{CV}$ at the whole basin scale, as shown in Figure 3(d). The high interannual CV values are distributed either in regions of the upper and middle basins where vegetation coverages are relatively low or in regions close to the rivers or water bodies. This is likely because the regions with low vegetation coverage are very unstable and sensitive to rainfall and runoff variations in the upper and middle basins; the variation in surface water level leads to the frequent transition between high vegetation coverage and swamp near the rivers or water bodies. The low interannual CV values are distributed in the regions with no vegetation coverage because these regions are significantly affected by desertification and in regions with high and stable vegetation coverage but which are far away from rivers or water bodies.

With the continuously increasing water discharge from the middle basin to the lower basin, the ecological situation of oases in the lower basin has significantly improved. For this study, several years of data from the oases in the lower basin are extracted from the NDVI data and shown in Figure 5. Because the water resources' management was implemented in 2001, the area of East Juyan Lake (depicted in black dotted lines) has increased significantly, at an average rate of approximately $4 \mathrm{~km}^{2}$ per year. The maximum area of the East Juyan Lake has reached $46.8 \mathrm{~km}^{2}$ in 2010 . The ecological impact of water resource reallocation is positive for the regions close to the East Juyan Lake. However, it is worth noting that water resource reallocation has not prevented the West Juyan Lake (depicted in red dotted lines) from shrinking; the vegetation in the regions close to the West Juyan Lake also shows a slight decreasing trend. The results indicate that the water resource reallocation only brought about benefits to the East Juyan Lake.

Though the vegetation has slight restoration trends in some regions, the vegetation coverage has not changed that much over the whole HRB. This may be because the ecosystem conservation projects have not been completely implemented in the upper basin; the improvement in water usage efficiency in the middle river basin, while not decreasing runoff to the lower regions, has limited impact on vegetation recovery in the middle basin.

4.2. Vegetation Transformation Characteristics. To identify the transformation speed quantitatively at the pixel level, the frequency distribution of the NDVI slope with mean NDVI for the upper, middle, and lower basins is shown in Figure 6 , where the domain of the mean NDVI is divided into seven intervals (i.e., $0-0.1 ; 0.1-0.2 ; 0.2-0.3$; $0.3-0.4 ; 0.4-$ $0.5 ; 0.5-0.6$; and $0.6-0.7)$. The domain of the NDVI slope is divided into five grades (i.e., <0; $0-20 ; 20-40 ; 40-60$; and $>60$ ) and defined as "degradation," "slow restoration," "medium restoration," "fast restoration," and "extremely fast restoration" for conducting subsequent analysis equidistantly based on the distribution of the NDVI slope. In the upper basin, the vegetated area (as represented by NDVI values more than 0.1 ) accounted for approximately $90 \%$ of the total area, and $38 \%$ of these areas were covered by relatively dense vegetation (with NDVI values more than 0.3). Approximately $84 \%$ of the total area in the upper basin showed vegetation restoration trends, leaving only $16 \%$ of the total area in vegetation degradation trends. Among the five intervals of the NDVI slope, "slow restoration" occupied most of the total area (approximately 40\%), followed by 30\% for "medium restoration" and $12 \%$ for "fast restoration." In the middle basin, the vegetated area accounted for approximately $44 \%$ of the total area, and only $16 \%$ of these areas were relatively densely vegetated. Approximately $92 \%$ of the total vegetation in the middle basin showed restoration trends, with only $8 \%$ in degradation trends. Among these restoration areas, $56 \%$ of them were "slow restoration" and $20 \%$ were "fast restoration" and "extremely fast restoration." In the lower basin, 96\% of the areas were covered by Gobi/desert (with NDVI values less than 0.1 ), leaving only $4 \%$ of the areas vegetated. $77 \%$ of the areas in the lower basin showed "slow restoration" and $18 \%$ showed "degradation," with these two parts explaining 95\% of the vegetation change trends in the lower basin. Overall, there was a vegetation restoration trend over the whole basin, and the fastest vegetation recovery occurred in regions where mean NDVI values were between 0.1 and 0.5 . The regions with nearly no vegetation (mean NDVI values between 0 and 0.1 ) occupied most of the basin and the restoration speed in these regions was slow; this might be because they are far away from the river (e.g., most desert regions in the lower basin).

To identify the transformation dispersion at the pixel level, the correlation between interannual $\mathrm{CV}$ and mean NDVI for the upper, middle, and lower basins is shown in Figure 7. The overall trends of interannual CVs in the whole basin showed a decrease with the increase in mean NDVI values, indicating that the regions with high vegetation cover were more stable than areas with low vegetation cover. The pattern is clearly shown in the upper basin in Figure 7(a); the regions with NDVI values less than 0.05 were highly unstable, and the corresponding CVs were between 0.1 and 1.2. CVs decreased to $0-0.2$ when NDVI values were between 0.05 and 0.1. Finally, CVs were small when NDVI values were more than 0.1 , which indicates a relatively stable status. Similar patterns also appear in the middle and lower basins, and the 


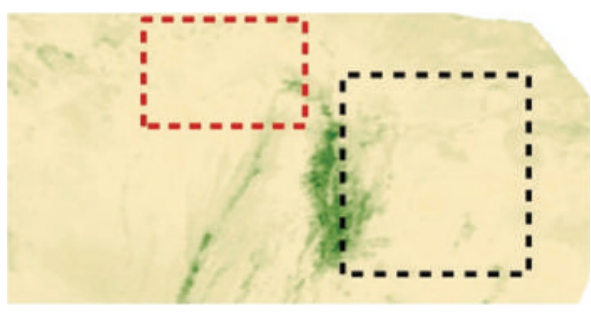

(a) 2000

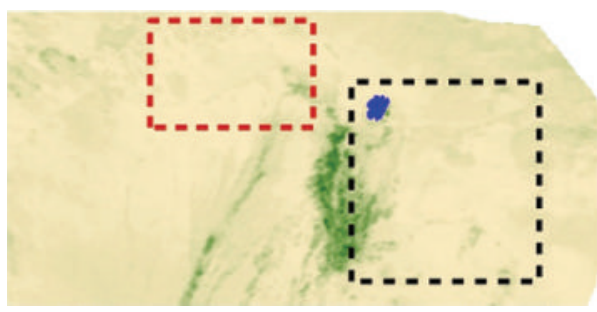

(c) 2004

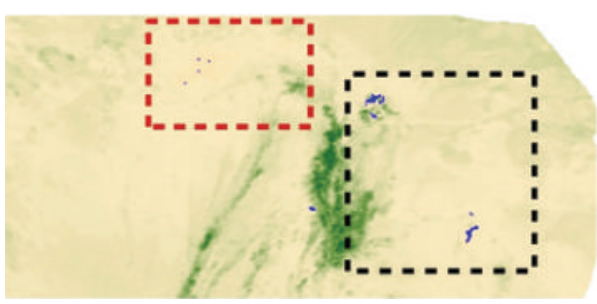

(e) 2008

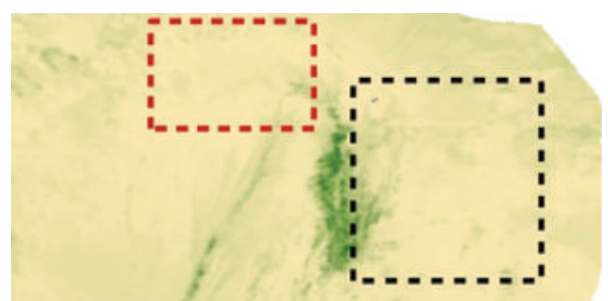

(b) 2002

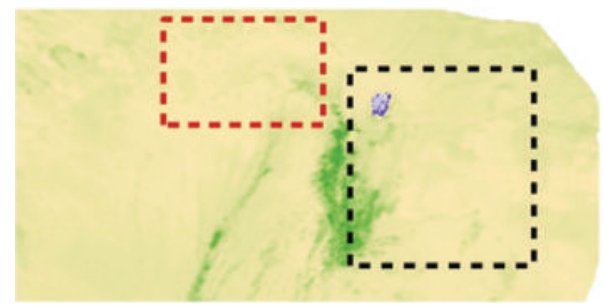

(d) 2006

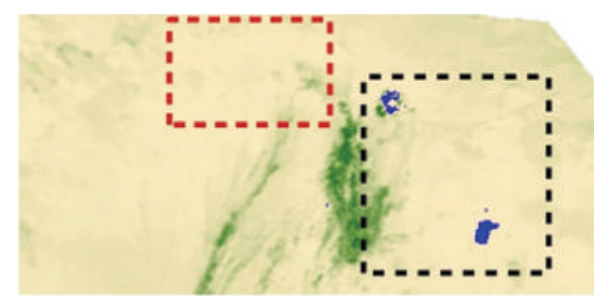

(f) 2010

FIGURE 5: Variations in water bodies in both East and West Juyan Lakes. ${ }^{*}$ The black and red dotted lines encompass the regions of the East and West Juyan Lakes, respectively.

correlations of CVs and mean NDVI were separated into two zones by a mean NDVI of approximately 0.05 . Thus, the mean NDVI of approximately 0.05 distinguished the stable regions from the unstable ones for the whole basin.

4.3. Vegetation Sensitivity in the Lower Basin. Water supply from the middle basin is the essential factor that dominates ecosystem restoration in the lower basin. As seen in Figure 8(a), the runoff changes at the ZYX, LXS, LXS West, and LXS East stations located in the downstream of the Heihe River show increasing trend after the implementation of water reallocation projects since 2001. Similarly, in Figure 8 (b), ratios of runoffs (i.e., ratio of runoff at the downstream stations to runoff at upstream YLX station) at the LXS and LXS stations also present increasing trends since 2001. That means an increase of water supply to the lower basin since the 2000s. On the other hand, the oases, which protect wildlife habitat and prevent fast desertification, are largely located in the lower basin. Thus, it is necessary to identify the temporal and spatial response of vegetation in the lower basin to the release from the middle basin. The correlations between NDVI data and releases of several past periods are studied, with significant and positive correlation points $(P \leq 0.05)$ picked out and shown in Figure 9 . Note that the historical release at the Langxinshan (LXS) hydrologic station is used for the correlations, and the " $n$ year(s) before" denotes the correlation between NDVI data of a period and water releases into this region $n$ year(s) before; for instance, in this case, "Two years before" means the correlation between NDVI data from 2001 to 2010 and water releases from 1999 to 2008, and "Current year" represents the relation between NDVI and water release in the same year.

From the perspectives of temporal and spatial responses, water release from the middle basin has a remarkable impact on vegetation in the lower basin. The affected vegetation ( $80 \%$ of the total area of the lower basin) is distributed in the regions within $50-100 \mathrm{~km}$ along the Heihe River and the East Juyan Lake. The vegetation affected by upstream water release with one-year time lag is distributed in the regions close to the Heihe River and the Badain Jaran Desert ( $40 \%$ of the total area of the lower basin). The regions with time lag more than two years are located near the Heihe River $(20 \%, 5 \%$, and nearly $0 \%$ of total area of the lower basin, with two, three, and four years' time lags, resp.). The correlation analysis results indicate that water release from the middle basin will generate accumulative efforts to vegetation in the lower basin within at most three years. Ecosystem restoration can only be achieved through continuous efforts in water supply increasing into the lower basin.

Figure 10 shows the distribution of specific time lags between anomalies of NDVI and runoff at the LXS station 


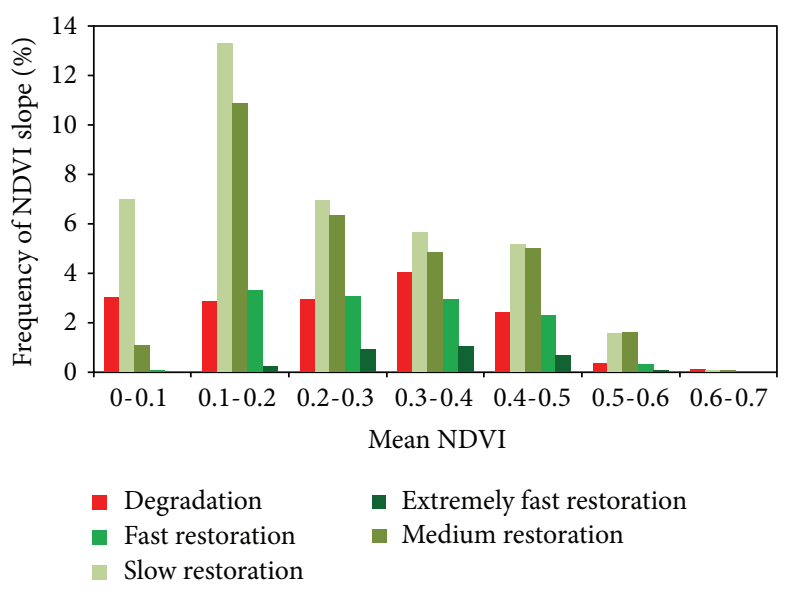

(a) The upper river basin

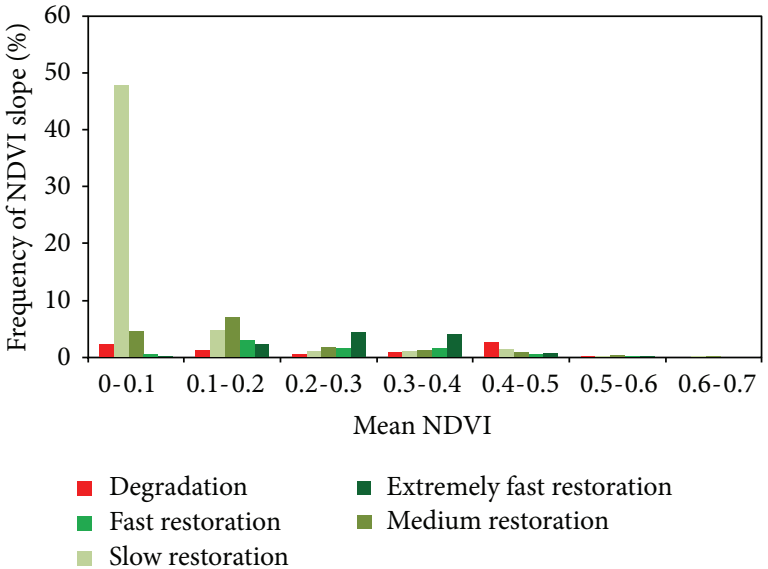

(b) The middle river basin

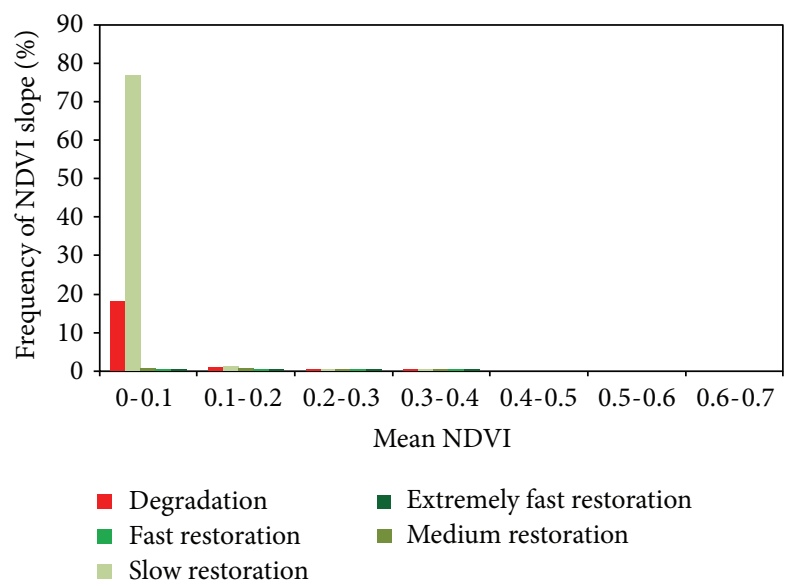

(c) The lower river basin

FIGURE 6: Frequency distribution of NDVI slope with mean NDVI.

in the derived pixels in Figure 9. Compared with Figure 9, vegetation along the Heihe River is influenced by runoff at the LXS station with time lag less than three years. Most of these regions are affected by runoff at the LXS station one year before. Additionally, regions along the West River are prominently impacted by the runoff one to two years before, while only small fractions at both the beginning and end of the East River have significant correlations with runoff anomalies. Except for regions along the river, a small area located at the west side of the West River also shows an obvious relation to runoff with one-year time lag.

\section{Conclusions}

In this study, the ecosystem restoration benefits in the upper, middle, and lower HRB are evaluated by identifying the vegetation dynamics and sensitivities in response to the near-term environmental conservation program in progress since 2001. Surface water area has significantly increased in the East Juyan Lake in the lower basin, but there is no obvious increase in the water body of the West Juyan Lake. Most regions in the basin have vegetation restoration trends, with the fastest increase in vegetation occurring in parts of the irrigation area in the middle basin and along the Heihe River in the lower basin. Parts of regions still show vegetation degradation trends, mainly located in the less vegetated area of the upper basin, some in the irrigation area in the middle basin and near the West Juyan Lake in the lower basin. In terms of the vegetation variation represented by the interannual $\mathrm{CV}$ values, the high variations are distributed in regions either close to the rivers and water bodies or with low vegetation coverage, which is caused by variation in the surface water level and the instability of less vegetated regions, respectively. The NDVI slope indicates that the fastest vegetation recovery occurs in regions with medium mean NDVI values (between 0.1 and 0.5 ) instead of the extremely sparsely (less than 0.1 ) and highly (more than 0.5 ) vegetated regions. The vegetation variations ( $C V s$ ) of the upper, middle, and lower basins are separated into two zones by an annual average NDVI value of approximately 0.05 ; 


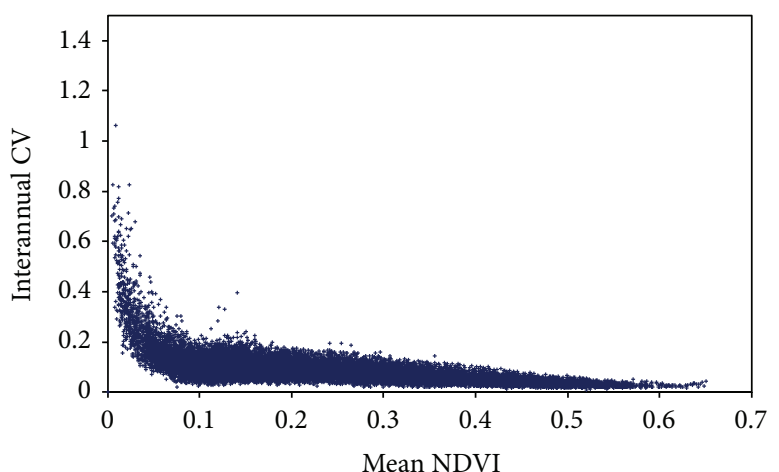

(a) The upper river basin

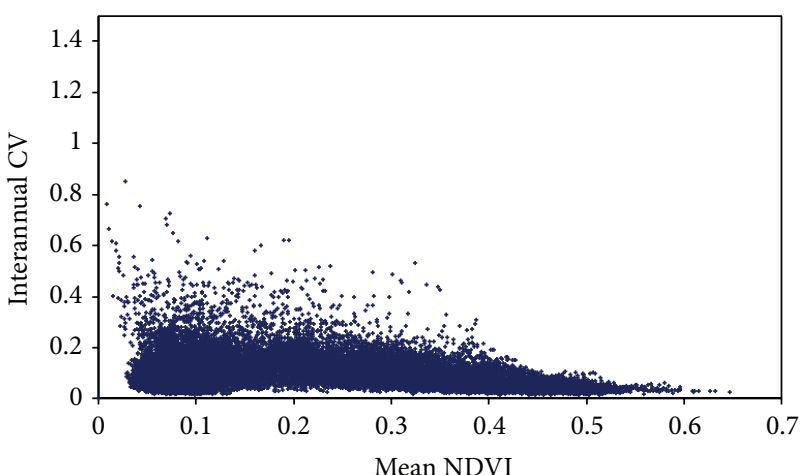

(b) The middle river basin

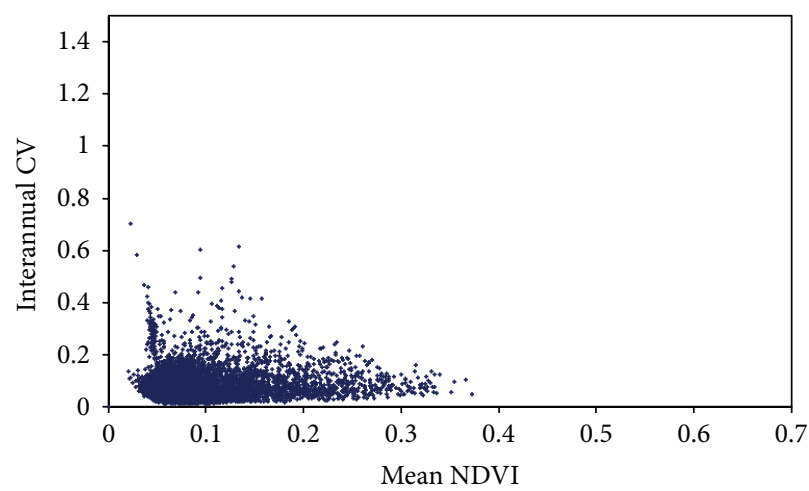

(c) The lower river basin

FIGURE 7: Relations between interannual CV and mean NDVI.

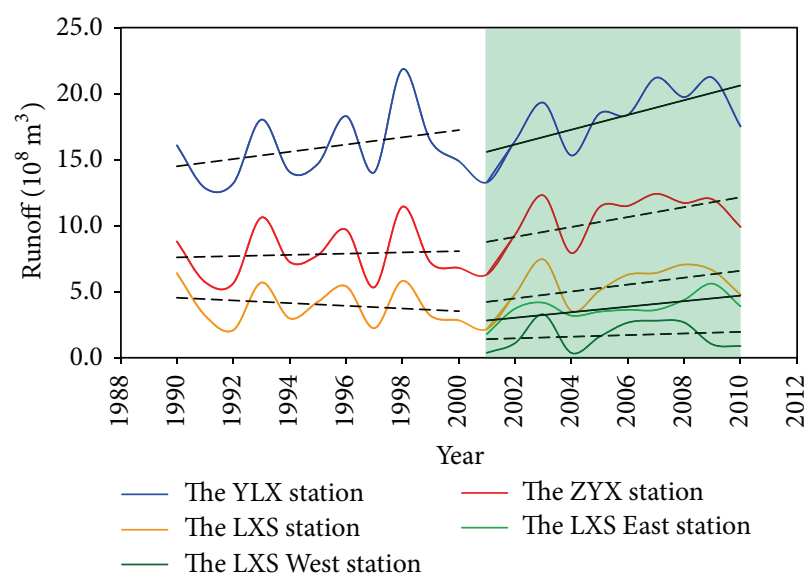

(a) Runoff changes at five stations

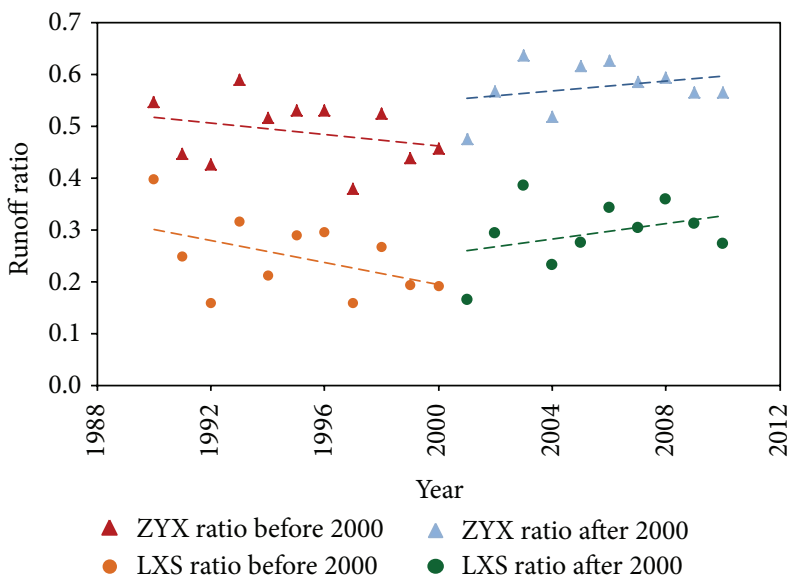

(b) Ratio changes of runoffs at the downstream ZYX and LXS stations to that at the upstream YLX station

Figure 8: Runoff variation in the Heihe River Basin before and after NTECP. ${ }^{*}$ Regression that is significant $(P \leq 0.05)$ or nonsignificant $(P>0.05)$ is presented with solid line or dashed line, respectively.

regions with mean NDVI values more than 0.05 and less than 0.05 show stable and unstable status, respectively. Finally, the correlation between vegetation and water release into the lower basin suggests that there is a prominent impact from the water supply (mainly the previous year's runoff) on the vegetation in the lower basin, particularly along the river. The significant impact of water supplement could last at most three years, and engineering or nonengineering measures should be maintained continuously for at least three years for permanent ecosystem recovery. 

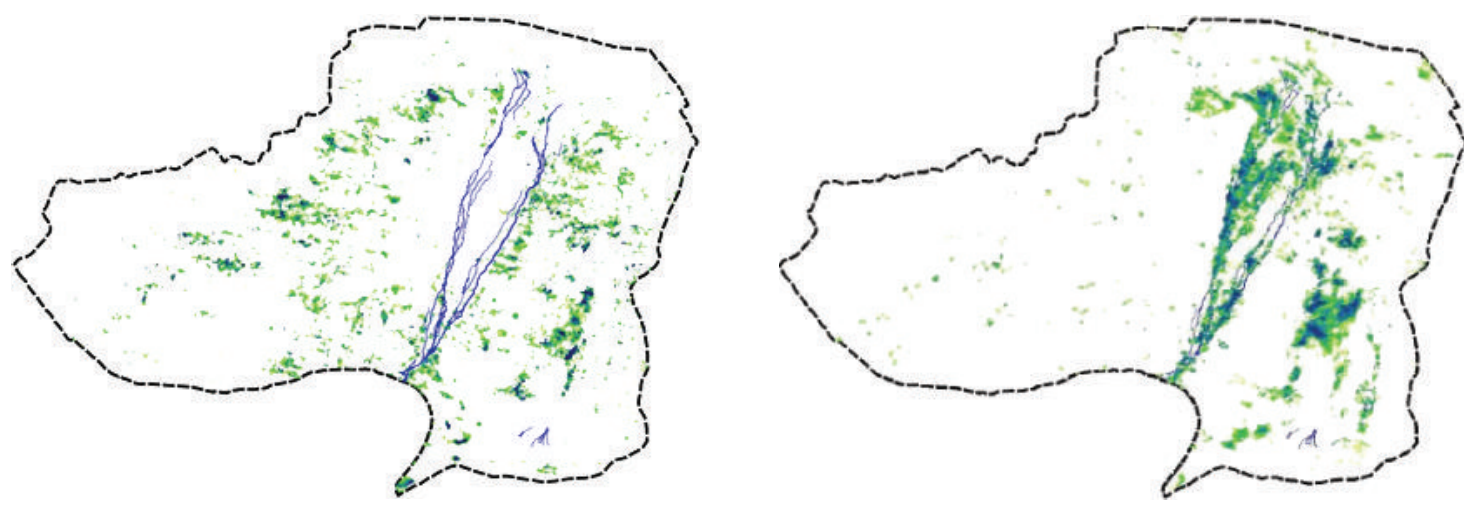

0.97

0.63

0.97

Correlation

(a) Current year

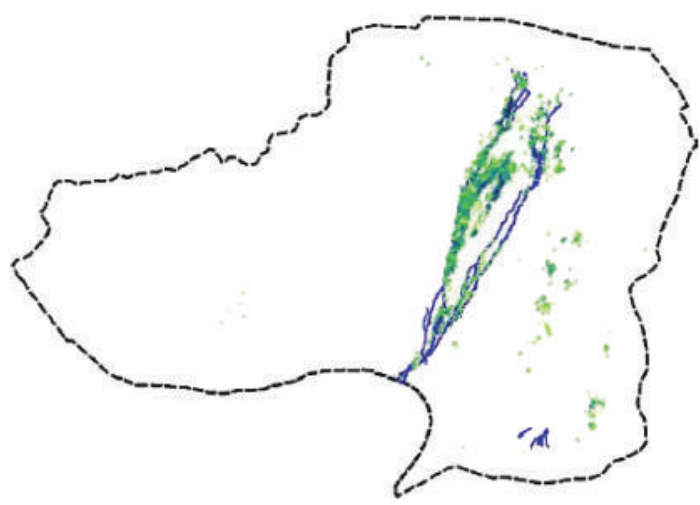

(b) Previous year

0.97

0.63

Correlation

(c) Two years before

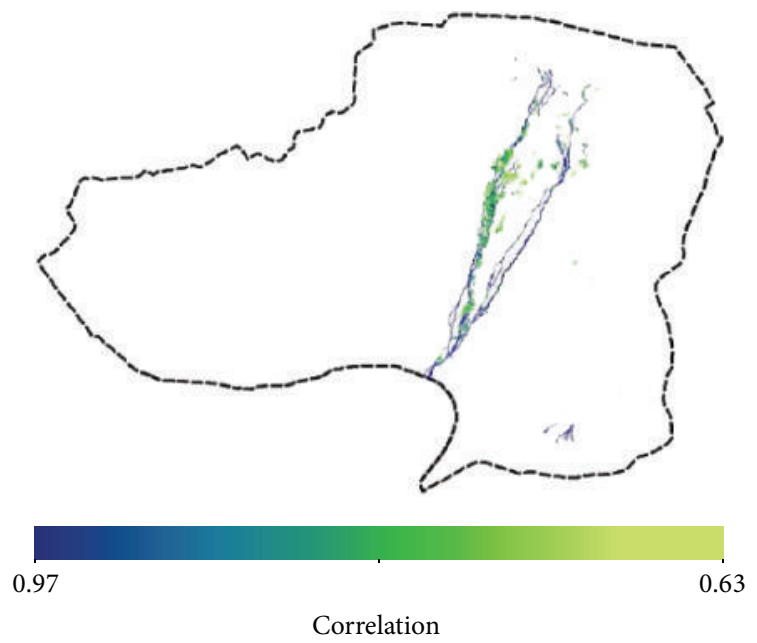

(d) Three years before
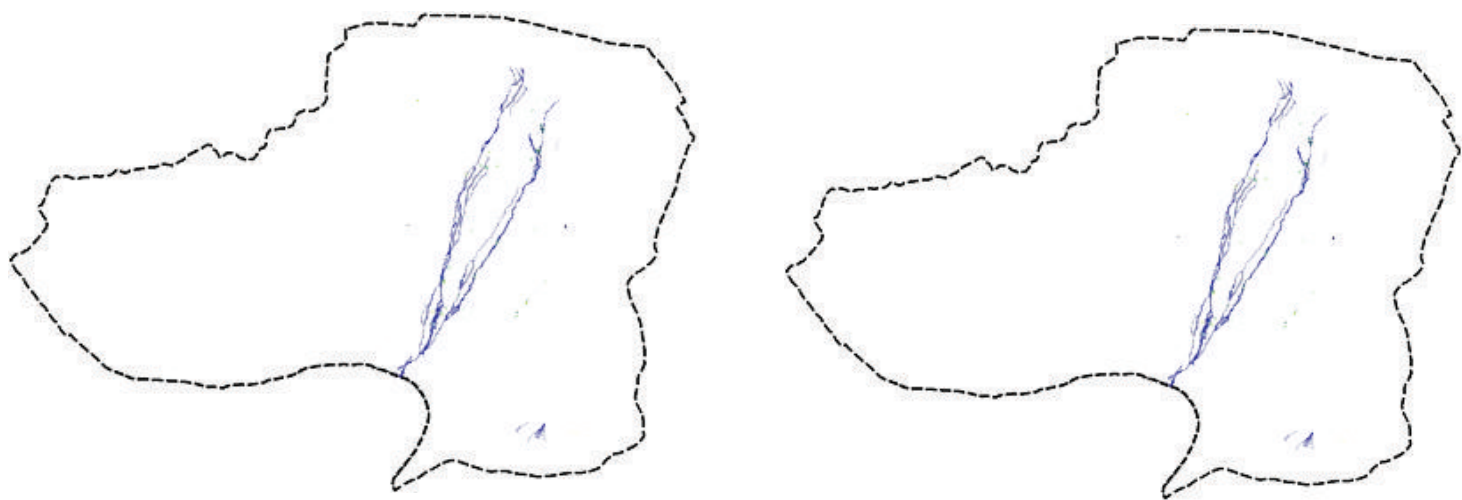

0.97

0.63

0.97

Correlation

(e) Four years before

(f)

FIgURE 9: Vegetation sensitivities to runoff in the lower Heihe River Basin. 


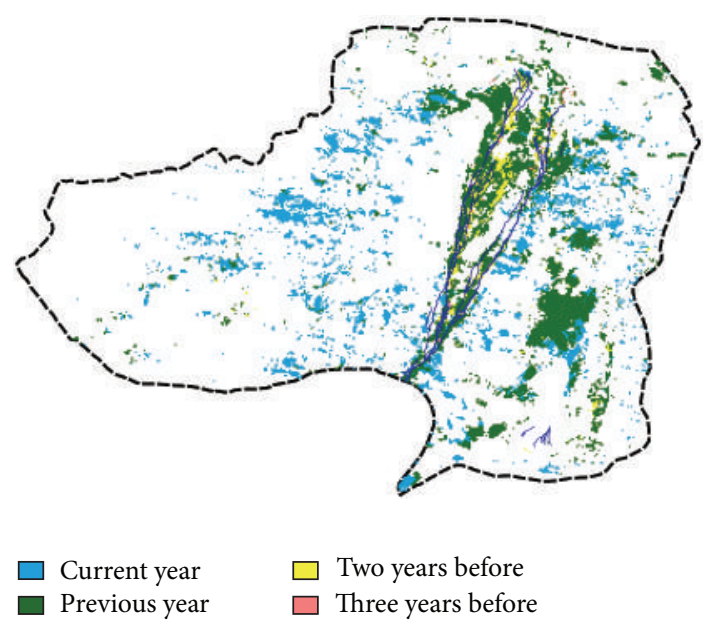

FIgURE 10: Time lag distribution between anomalies of NDVI and runoff at the Langxinshan station at the pixel level.

\section{Conflict of Interests}

The authors declare that there is no conflict of interests regarding the publication of this paper.

\section{Acknowledgments}

This paper is financially supported by the National Natural Science Foundation of China (91125018), the National Key Science and Technology Project Fund from the Ministry of Science and Technology (MOST) during the Twelfth Five-Year Project (2013BAB05B03), and the Research and Development Special Fund for Public Welfare Industry of the Ministry of Water Research in China (201301081).

\section{References}

[1] L. Jia, H. Shang, G. Hu, and M. Menenti, "Phenological response of vegetation to upstream river flow in the Heihe Rive basin by time series analysis of MODIS data," Hydrology and Earth System Sciences, vol. 15, no. 3, pp. 1047-1064, 2011.

[2] Y.-C. Zhang, J.-J. Yu, M.-Y. Qiao, and H.-W. Yang, "Effects of eco-water transfer on changes of vegetation in the lower Heihe River basin," Journal of Hydraulic Engineering, vol. 42, no. 7, pp. 757-765, 2011.

[3] P. Wang, J. Yu, Y. Zhang, and C. Liu, "Groundwater recharge and hydrogeochemical evolution in the Ejina Basin, northwest China," Journal of Hydrology, vol. 476, pp. 72-86, 2013.

[4] Ministry of Water Resources (MWR), Recent Management Planning for Heihe River Basin (China), China Water Power Press, Beijing, China, 2001.

[5] R. A. Pielke Sr., R. Avissar, M. Raupach, A. J. Dolman, X. Zeng, and A. S. Denning, "Interactions between the atmosphere and terrestrial ecosystems: influence on weather and climate," Global Change Biology, vol. 4, no. 5, pp. 461-475, 1998.

[6] L. Bounoua, F. G. Hall, P. J. Sellers et al., "Quantifying the negative feedback of vegetation to greenhouse warming: a modeling approach," Geophysical Research Letters, vol. 37, no. 23, 2010.
[7] R. B. Myneni, C. D. Keeling, C. J. Tucker, G. Asrar, and R. R. Nemani, "Increased plant growth in the northern high latitudes from 1981 to 1991," Nature, vol. 386, no. 6626, pp. 698-702, 1997.

[8] R. J. Donohue, M. L. Roderick, T. R. McVicar, and G. D. Farquhar, "Impact of $\mathrm{CO}_{2}$ fertilization on maximum foliage cover across the globe's warm, arid environments," Geophysical Research Letters, vol. 40, no. 12, pp. 3031-3035, 2013.

[9] Y. Wang, M. L. Roderick, Y. Shen, and F. Sun, "Attribution of satellite-observed vegetation trends in a hyper-arid region of the Heihe River basin, Western China," Hydrology and Earth System Sciences, vol. 18, no. 9, pp. 3499-3509, 2014.

[10] D. A. Devitt, A. Sala, K. A. Mace, and S. D. Smith, "The effect of applied water on the water use of saltcedar in a desert riparian environment," Journal of Hydrology, vol. 192, no. 1, pp. 233-246, 1997.

[11] D. Gries, F. Zeng, A. Foetzki et al., "Growth and water relations of Tamarix ramosissima and Populus euphratica on Taklamakan desert dunes in relation to depth to a permanent water table," Plant, Cell and Environment, vol. 26, no. 5, pp. 725-736, 2003.

[12] G. Wang, J. Q. Liu, J. Kubota, and L. Chen, "Effects of land-use changes on hydrological processes in the middle basin of the Heihe River, northwest China," Hydrological Processes, vol. 21, no. 10, pp. 1370-1382, 2007.

[13] M. Ryner, K. Holmgren, and D. Taylor, "A record of vegetation dynamics and lake level changes from Lake Emakat, northern Tanzania, during the last c. 1200 years," Journal of Paleolimnology, vol. 40, no. 2, pp. 583-601, 2008.

[14] A. J. Elmore, S. J. Manning, J. F. Mustard, and J. M. Craine, "Decline in alkali meadow vegetation cover in California: the effects of groundwater extraction and drought," Journal of Applied Ecology, vol. 43, no. 4, pp. 770-779, 2006.

[15] P. Wang, Y. Zhang, J. Yu, G. Fu, and F. Ao, "Vegetation dynamics induced by groundwater fluctuations in the lower Heihe River Basin, northwestern China," Journal of Plant Ecology, vol. 4, no. 1-2, pp. 77-90, 2011.

[16] C. J. Tucker, "Red and photographic infrared linear combinations for monitoring vegetation," Remote Sensing of Environment, vol. 8, no. 2, pp. 127-150, 1979.

[17] M. Schlerf, C. Atzberger, and J. Hill, "Remote sensing of forest biophysical variables using HyMap imaging spectrometer data," Remote Sensing of Environment, vol. 95, no. 2, pp. 177-194, 2005.

[18] A. R. Huete, "A soil-adjusted vegetation index (SAVI)," Remote Sensing of Environment, vol. 25, no. 3, pp. 295-309, 1988.

[19] A. A. Gitelson, F. Kogan, E. Zakarin, L. Spivak, and L. Lebed, "Using AVHRR data for quantitive estimation of vegetation conditions: calibration and validation," in Synergistic Use of Multisensor Data for Land Processes, B. J. Choudhury, S. Tanaka, A. Kondo, M. Menenti, and F. Becker, Eds., pp. 673-676, 1998.

[20] A. Huete, K. Didan, T. Miura, E. P. Rodriguez, X. Gao, and L. G. Ferreira, "Overview of the radiometric and biophysical performance of the MODIS vegetation indices," Remote Sensing of Environment, vol. 83, no. 1-2, pp. 195-213, 2002.

[21] D. Y. Chen and W. Brutsaert, "Satellite-sensed distribution and spatial patterns of vegetation parameters over a tallgrass prairie," Journal of the Atmospheric Sciences, vol. 55, no. 7, pp. 1225-1238, 1998.

[22] E. Weiss, S. E. Marsh, and E. S. Pfirman, "Application of NOAAAVHRR NDVI time-series data to assess changes in Saudi Arabia's rangelands," International Journal of Remote Sensing, vol. 22, no. 6, pp. 1005-1027, 2001. 
[23] R. Amri, M. Zribi, Z. Lili-Chabaane, B. Duchemin, C. Gruhier, and A. Chehbouni, "Analysis of vegetation behavior in a North African semi-arid region, using SPOT-VEGETATION NDVI data," Remote Sensing, vol. 3, no. 12, pp. 2568-2590, 2011.

[24] E. O. Box, B. N. Holben, and V. Kalb, "Accuracy of the AVHRR vegetation index as a predictor of biomass, primary productivity and net $\mathrm{CO}_{2}$ flux," Vegetatio, vol. 80, no. 2, pp. 71-89, 1989.

[25] R. Fensholt, K. Rasmussen, P. Kaspersen, S. Huber, S. Horion, and E. Swinnen, "Assessing land degradation/recovery in the african sahel from long-term earth observation based primary productivity and precipitation relationships," Remote Sensing, vol. 5, no. 2, pp. 664-686, 2013.

[26] C. J. Tucker, J. R. G. Townshend, and T. E. Goff, "African landcover classification using satellite data," Science, vol. 227, no. 4685, pp. 369-375, 1985.

[27] S. Moulin, L. Kergoat, N. Viovy, and G. Dedieu, "Global-scale assessment of vegetation phenology using NOAA/AVHRR satellite measurements," Journal of Climate, vol. 10, no. 6, pp. 1154-1170, 1997.

[28] Y. Gu, J. F. Brown, J. P. Verdin, and B. Wardlow, "A five-year analysis of MODIS NDVI and NDWI for grassland drought assessment over the central Great Plains of the United States," Geophysical Research Letters, vol. 34, no. 6, Article ID L06407, 2007.

[29] P. L. Nagler, J. Cleverly, E. Glenn, D. Lampkin, A. Huete, and Z. Wan, "Predicting riparian evapotranspiration from MODIS vegetation indices and meteorological data," Remote Sensing of Environment, vol. 94, no. 1, pp. 17-30, 2005.

[30] X. Jin, M. Schaepman, J. Clevers, Z. Su, and G. Hu, "Correlation between annual runoff in the Heihe River to the vegetation cover in the Ejina Oasis (China)," Arid Land Research and Management, vol. 24, no. 1, pp. 31-41, 2010.

[31] W. Yaobin, F. Qi, S. Jianhua, S. Yonghong, C. Zongqiang, and X. Haiyang, "The changes of vegetation cover in Ejina Oasis based on water resources redistribution in Heihe River," Environmental Earth Sciences, vol. 64, no. 7, pp. 1965-1973, 2011.

[32] Y. Zhang, J. Yu, P. Wang, and G. Fu, "Vegetation responses to integrated water management in the Ejina basin, northwest China," Hydrological Processes, vol. 25, no. 22, pp. 3448-3461, 2011.

[33] I. Harris, P. D. Jones, T. J. Osborn, and D. H. Lister, "Updated high-resolution grids of monthly climatic observations-the CRU TS3.10 Dataset," International Journal of Climatology, vol. 34, no. 3, pp. 623-642, 2014.

[34] NASA, "National Aeronautics and Space Administration Earth Observing System Data and Information System," http://reverb .echo.nasa.gov/.

[35] J. Chen, P. Jönsson, M. Tamura, Z. Gu, B. Matsushita, and L. Eklundh, "A simple method for reconstructing a high-quality NDVI time-series data set based on the Savitzky-Golay filter," Remote Sensing of Environment, vol. 91, no. 3-4, pp. 332-344, 2004.

[36] C. J. Tucker, D. A. Slayback, J. E. Pinzon, S. O. Los, R. B. Myneni, and M. G. Taylor, "Higher northern latitude normalized difference vegetation index and growing season trends from 1982 to 1999," International Journal of Biometeorology, vol. 45, no. 4, pp. 184-190, 2001.

[37] S. R. Karlsen, A. Tolvanen, E. Kubin et al., "MODIS-NDVIbased mapping of the length of the growing season in northern Fennoscandia," International Journal of Applied Earth Observation and Geoinformation, vol. 10, no. 3, pp. 253-266, 2008. 

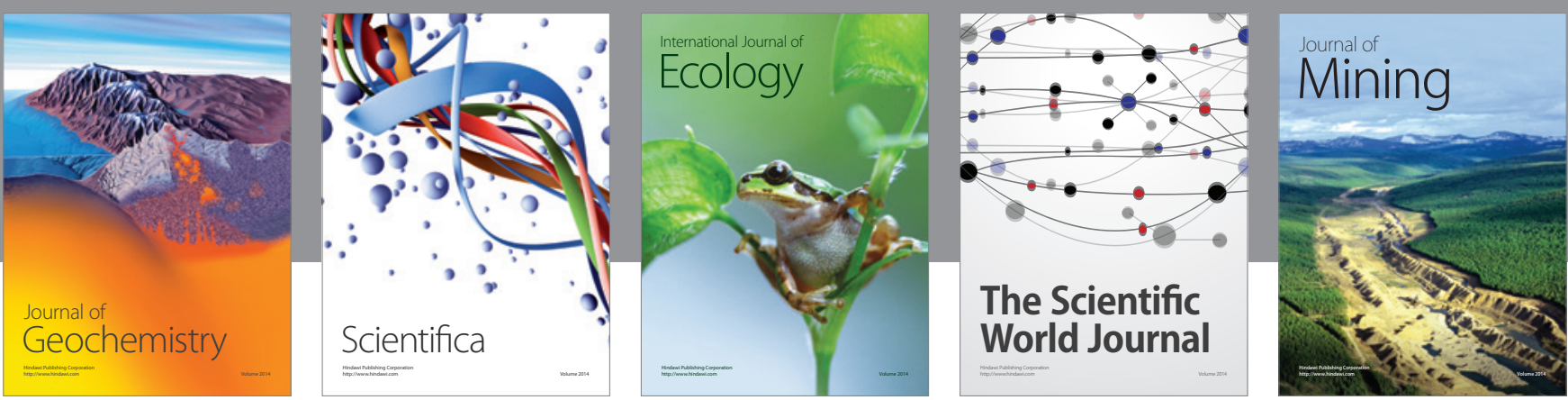

The Scientific World Journal
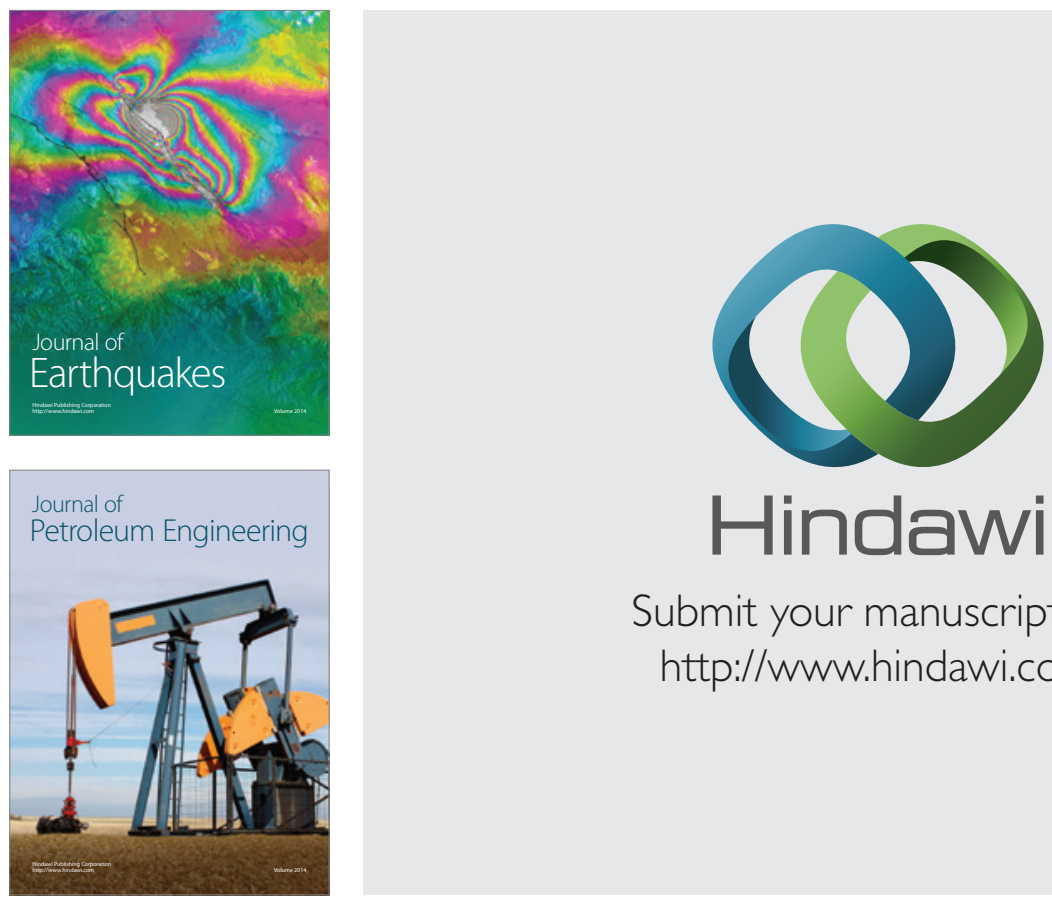

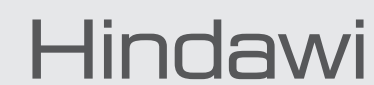

Submit your manuscripts at

http://www.hindawi.com
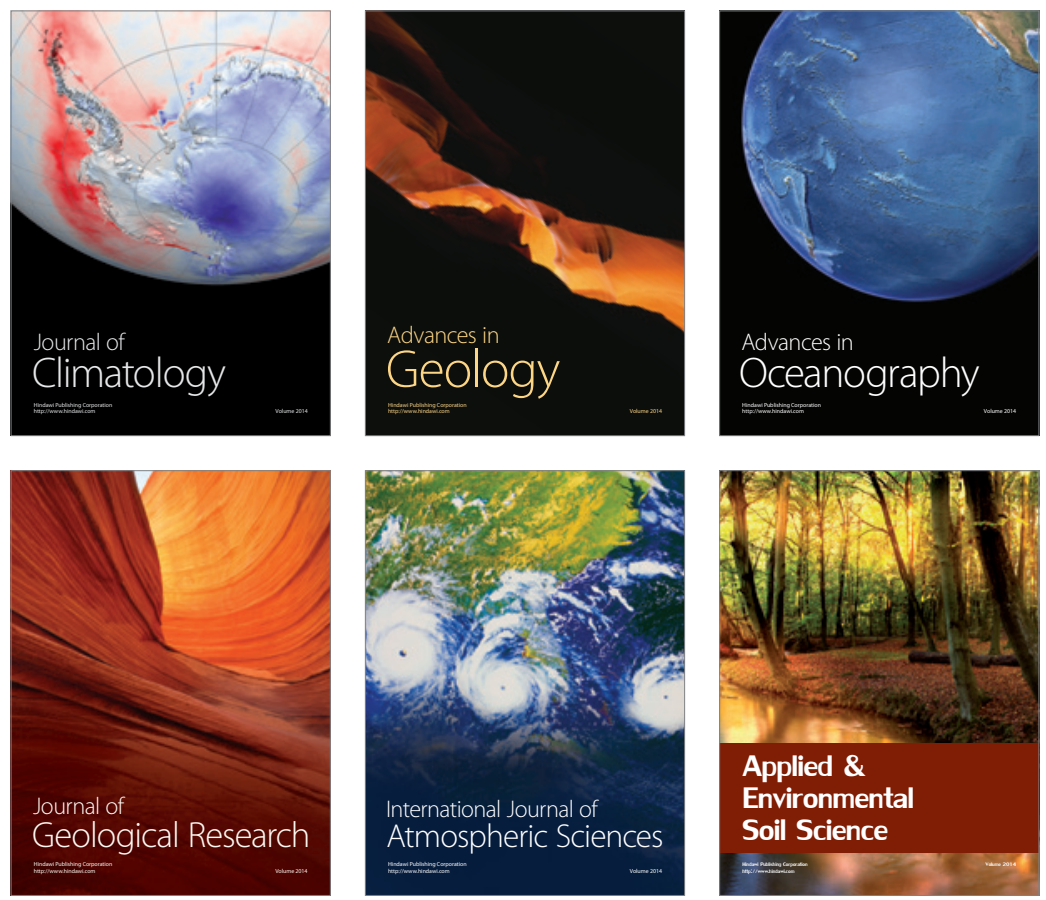
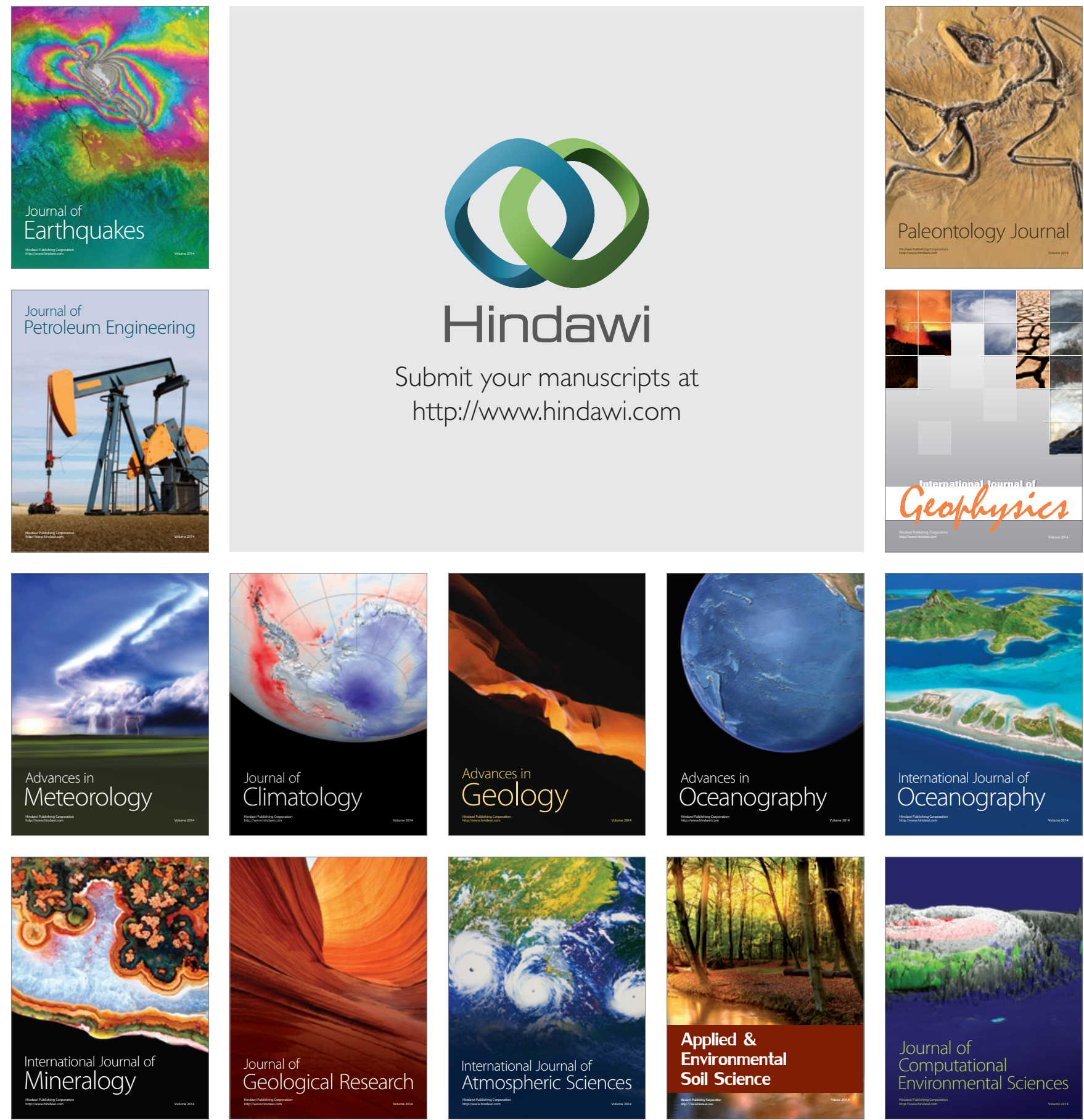